\title{
ANÁLISE DE PROCESSOS E OPORTUNIDADES DE MELHORIAS EM UMA EMPRESA DE SERVIÇOS
}

\section{ANALYSIS OF PROCESSES AND OPPORTUNITIES FOR IMPROVEMENT IN A SERVICE COMPANY}

\author{
Guilherme Luiz Müller* glmuller@hotmail.com \\ Letícia Diesel* Idiesel@unisc.br \\ Miguel Afonso Sellitto** sellitto@unisinos.br \\ *Universidade de Santa Cruz - UNISC \\ ${ }^{*}$ Universidade do Vale do Rio dos Sinos - UNISINOS
}

\begin{abstract}
Resumo: O objetivo deste artigo é apresentar um estudo de caso no qual foram analisados os processos de uma empresa de prestação de serviços de cobrança de clientes em atraso com instituições financeiras. O principal objetivo estratégico da empresa é acelerar seus processos e reduzir o prazo até a conclusão dos serviços. Os processos foram mapeados, as ineficiências foram identificadas e sugestões de melhorias foram apresentadas. Foram usados fluxogramas e organogramas. A principal ineficiência identificada foi 0 desbalanceamento entre atividades em sequência, devido à forma com que a empresa organizou sua atividade produtiva. A reorganização das equipes por processos e não por clientes trouxe equilíbrio às atividades e eliminou gargalos. Outra ineficiência encontrada foi a sobrecarga em recurso escasso, a equipe de advogados. $O$ rearranjo permitiu que atividades fossem redirecionadas para recurso ocioso, a equipe de funcionários administrativos. Após as mudanças, o prazo de atendimento médio caiu de 61 para 40 dias e o percentual de atendimentos no prazo subiu de 12 para $81 \%$.
\end{abstract}

Palavras-chave: Análise de processos. Gestão de serviços. Reengenharia de processos. Mapeamento de processos.

\begin{abstract}
The aim of this paper is to present a case study which analyzed the processes of a company providing billing services for customers in arrears with financial institutions. The main strategic objective of the company is accelerating its processes, in order to reduce the time until the completion of service. The processes were mapped, the inefficiencies were identified and suggestions for improvements were presented. We used flow charts and organizational charts. The main inefficiency identified was unbalanced sequential activities, due to how the company organized its operations. The reorganization of the teams on a process basis, not by customers, balanced the activities and eliminated bottlenecks. Another point of inefficiency was found in overloading a scarce resource, the team of lawyers. The rearrangement has allowed activities to be redirected to idle resource, the administrative staff. After the changes, the average term of service fell from 61 to 40 days and the percentage of attendances in period rose from 12 to $81 \%$.
\end{abstract}

Key-words: Process analysis. Service management. Process reengineering. Service strategy. Process mapping. 


\section{INTRODUÇÃO}

A necessidade de melhorar os níveis de serviço aos clientes tem levado as empresas de serviços financeiros, e em particular as empresas de cobrança, a buscar novas alternativas de gestão. Tem sido observado no setor um acréscimo na concorrência interna, tanto entre as empresas de cobrança quanto entre as instituições que financiam os clientes. Uma alternativa que o setor tem usado é a terceirização de processos de apoio, tais como as carteiras de cobrança, ou seja, as cobranças de financiados inadimplentes. Como a economia brasileira depende de crédito mais do que as economias de outras nações, o fenômeno da inadimplência no Brasil não é de pequena monta. Existe, portanto, mercado para empresas de cobrança, havendo concorrência e rivalidade no setor. Segundo Zerbini (2006), a terceirização de atividade de serviços financeiros, incluindo cobranças, cresceu mais de $12 \%$ nos cinco anos precedentes à sua pesquisa. Segundo o autor, na época, o volume de serviços financeiros terceirizado atingiu cerca de $30 \%$ do volume de atividades financeiras em grandes empresas de vendas de bens de consumo e de veículos. Estas são os principais clientes das empresas terceirizadas de serviços de cobrança.

No setor de serviços financeiros, a competitividade está ligada principalmente ao cumprimento dos prazos exigidos pelos clientes. Em muitos casos, são necessários estudos de melhoria ou reengenharia de processos. Técnicas de redesenho de processos foram usadas nos programas de Gestão da Qualidade Total, incluindo métodos de solução de problemas por identificação de causas, buscando a melhoria do desempenho sob o ponto de vista do cliente (GALLINA et al., 2006).

Para Davenport (1994), melhorias nos processos são representativas para o resultado da empresa. $O$ autor sugere focar esforços em processos-chave, que devem ser replanejados para atender múltiplos objetivos de negócios, dentre estes a redução de tempos. Para Adesola e Baines (2005), após o redesenho e implementação das modificações, é necessária monitoração dos resultados para aperfeiçoamento contínuo do novo processo. Para Gonçalves (2000), nem todos os

processos têm a mesma importância, tanto sob o ponto de vista dos resultados 
como dos recursos envolvidos. O autor pergunta: quais são os processos mais importantes na empresa? Algumas respostas possíveis são: os de maior orçamento, os de maior impacto no funcionamento da empresa ou os processos responsáveis pela maior parcela na geração de valor para o cliente. A prioridade dos processos pode ser avaliada pela importância relativa ou pelo valor econômico que podem gerar. Para o autor, o conceito de EVA também pode ser utilizado para priorizar processos.

A principal exigência de desempenho que instituições bancárias e financeiras fazem em relação às operações de cobrança é o cumprimento de prazos. Segundo Paiva et al. (2004), são critérios estratégicos de competição típicos de uma operação: (i) custo; (ii) qualidade; (iii) desempenho de entrega; (iv) flexibilidade; (v) serviços associados ao produto; e (vi) inovatividade. Observando em uma perspectiva de estratégia de operações, o principal objetivo estratégico da empresa estudada é competir reduzindo o prazo de entrega dos serviços contratados, ou seja, pelo terceiro critério, desempenho de entrega.

O objetivo deste artigo é sugerir melhorias que possam reduzir os prazos de atendimento no serviço de cobrança que uma empresa terceirizada de serviços financeiros presta a seus clientes. A questão de pesquisa foi: como reduzir o tempo até a conclusão do serviço que uma empresa terceirizada de cobrança presta a seus clientes? O serviço consiste na cobrança extrajudicial de financiados inadimplentes ou de ajuizamento das dívidas, quando a cobrança direta não é bem sucedida. Os bens financiados são tipicamente eletrodomésticos, móveis e veículos. Os objetivos específicos do artigo são: (i) mapear os atuais processos da empresa; (ii) identificar ineficiências que atrasam os atuais processos; e (iii) propor melhorias que possam aumentar a competitividade da empresa, principalmente reduzindo o tempo até o ajuizamento do processo de cobrança. O método de trabalho foi: (i) mapeamento do macro-processo da empresa e identificação da causa principal para que não se cumpram os prazos de clientes; (ii) mapeamento dos processos intermediários e identificação de ineficiências que o atrasam; (iii) proposta de melhorias que acelerem o processo; e (iv) verificação dos primeiros resultados. Não foi objetivo de pesquisa o acompanhamento de longo prazo dos resultados, pois estes requerem maior tempo de observação e dependem do amadurecimento da mudança e da 
cristalização de suas decorrências. Tal objetivo foi remetido à continuidade de pesquisa.

O método de pesquisa foi o estudo de caso. O método investiga e preserva as características dos eventos da vida real, tais como ciclos de vida individuais, processos organizacionais e administrativos, mudanças em regiões urbanas, relações internacionais e a maturação de alguns setores. O estudo de caso lida com múltiplas fontes de evidências, investigando um tópico empírico segundo procedimentos pré-especificados. O objeto de um estudo de caso é uma unidade que se analisa profundamente (TRIVIÑOS, 2001; YIN, 2001).

Trata-se de pesquisa qualitativa e também quantitativa. As técnicas de pesquisa foram a observação participante, a entrevista e a análise dos processos de trabalho da empresa, estas qualitativas. A observação participante envolveu interação entre o pesquisador e os informantes no meio destes últimos. Como o objetivo da pesquisa incluiu a redução de prazos de entrega para aumento da competitividade, a medição e o eventual controle desta variável exigiram o uso de técnicas quantitativas, tais como a tabulação de resultados de desempenho disponíveis nos arquivos da empresa. Foi feita uma medição do prazo de atendimento dos dois meses anteriores e mais uma medição seis meses após a intervenção.

Segundo Eckstein (1975 apud ROESCH, 1999), um estudo de caso pode contribuir de cinco modos para uma teoria: oferecer uma descrição profunda e específica de um objeto; interpretar eventuais regularidades como evidências de postulados teóricos mais gerais, ainda não verificados; criar uma situação deliberadamente para testar uma idéia; fazer sondagens plausíveis acerca de uma teoria e estudar o caso crucial, que apóia ou refuta a teoria. Entende-se que este estudo de caso contribua como no primeiro e no segundo tipo: descreve em profundidade os processos de uma empresa de cobrança e interpreta eventuais regularidades observadas, coletando informações para uma futura teoria fundamentada sobre o tema. As conclusões devem se restringir ao caso estudado, não sendo ainda passíveis de generalização. A contribuição desta pesquisa é o relato em profundidade de um caso que, somado a outros, pode contribuir para a 
construção de uma teoria envolvendo estratégias de gerenciamento de serviços terceirizados de cobrança de inadimplentes.

O restante do artigo está organizado em: (i) revisão bibliográfica; (ii) relato da pesquisa; (iii) discussão dos resultados; e (iv) continuidade.

\section{GERENCIAMENTO DE PROCESSOS}

Processos descrevem como as coisas são feitas dentro de uma empresa. É um conjunto formado por entradas, processamento e saídas de produto, serviço e informação. Para Werkena (1995), um processo é um conjunto de causas cujo objetivo é produzir um efeito observável, o produto do processo. Para Hammer e Champy (1994), processo empresarial é um conjunto de atividades que possuem um ou mais tipos de entrada, gerando uma saída de valor para o cliente, ou seja, a entrega do produto ou serviço ao cliente. Para Cruz (2003), processos de negócios são atividades que objetivam transformar entradas ou insumos em bens ou serviços (saídas) que serão entregues a clientes, com agregação de valor ao longo das atividades. Para Davenport (1994), um processo é um conjunto de atividades estruturadas que resultam em um produto especificado para um determinado cliente ou mercado. Processo, portanto, é uma ordenação lógica de atividades interligadas, cujo objetivo é produzir produtos ou serviços que representem valor para clientes. São características essenciais de processos a regularidade, a previsibilidade do resultado e o conhecimento das condições para sua realização (KIM; JANG, 2002).

A gestão do processo pressupõe ciclos de aprendizado e exige sistematização do conhecimento (RINALDI JÚNIOR, 2006). Para Davenport (2002), as empresas deveriam padronizar seus processos, de preferência desenvolvendo-os de maneira integrada a clientes e fornecedores, criando e maturando modelos de excelência nas indústrias em que atuam. Para Davenport (1994), as atividades empresariais devem ser analisadas pelos seus processos-chave e não por suas funções, departamentos ou produtos. Uma das técnicas que trata com tais objetivos é a reengenharia de processos, criando uma visão processual da atividade. É pela visão de processo que a empresa compreende o papel que exerce na satisfação dos 
clientes. Com a visualização dos processos, através de seus fluxos, é possível redesenhar a forma de fazer as coisas buscando redução de custos e melhorias, tanto para os clientes internos como para os externos (KIM; JANG, 2002).

Uma forma de entender como a organização se estrutura e como funcionam seus processos é a análise dos macrofluxos. A construção e a leitura dos macrofluxos permitem conhecer como as atividades acontecem ao longo dos processos. A partir desta leitura, pode-se definir qual processo será aprofundado para que seja possível identificar o potencial de melhoria a objetivar (CRUZ, 2004). Para Davenport (1994), há pelo menos quatro razões para documentar processos antes de propor melhorias: (i) o entendimento dos atuais processos facilita a comunicação entre os gestores da empresa; (ii) em organizações complexas, é difícil passar para um novo processo sem compreender o atual, pois pode-se descartar operações importantes no redesenho; (iii) o reconhecimento de problemas existentes no atual processo pode ajudar a evitar sua repetição no novo processo; e (iv) o entendimento dos atuais processos possibilita mensurar o valor da reengenharia proposta.

Em processos encadeados, a saída de um processo é a entrada do processo seguinte. Muitas vezes, um processo encadeado tem como resultado final menos do que a capacidade da maior operação individual, seja porque a demanda é insuficiente, seja pela variabilidade entre as partes, seja porque há desbalanceamentos importantes ao longo do fluxo. As etapas que operam na capacidade máxima são os gargalos do processo encadeado e limitam sua capacidade de gerar resultado. Gargalos surgem por desbalanceamento intrínseco ou como resultado de políticas de utilização dos recursos. A ideal é que se encontre equilíbrio entre atividades sequenciais. Recursos restringidos determinam a capacidade de produção do processo e podem ser usados para controlar o fluxo através do sistema. Para tanto, é necessário identificá-los. Para aumentar a capacidade de um processo, basta aumentar a capacidade dos gargalos ou identificar as atividades que não precisam passar por eles e alocá-las a caminhos alternativos (SLACK et al., 2002; GOLDRATT; COX, 2002). 


\subsection{Mapeamento de processos e reengenharia}

O mapeamento de processos pode ser útil para a identificação dos processos essenciais e para análise sistêmica das organizações. O principal objetivo do mapeamento dos processos é entender e comunicar o fluxo das atividades e as transformações que ocorrem no interior do processo. Por este entendimento, é possível propor melhorias nos serviços prestados ou produtos fabricados. Pelo mapeamento, processos complexos podem ser estruturados e visualizados, o que pode auxiliar na identificação de atividades que não agregam valor aos clientes. $O$ produto do mapeamento de processos é o mapa geral de processos. Definido este mapa, inicia-se a priorização dos processos que serão detalhados. O mapeamento estruturado com a definição de padrões de documentação permite analisar todo o potencial de integração e otimização existente. De forma complementar, são identificados os atributos dos processos, o que permite realizar estudos de custeio ou dimensionar o tamanho da equipe que deverá realizá-lo (KIM; JANG, 2002).

Para Johansson (1995), uma organização é tão efetiva quanto o forem seus processos, pois estes são os responsáveis pelo que será ofertado ao cliente. Para Pinho et al. (2006), as técnicas de mapeamento de processo devem ser selecionadas de acordo com as características do processo e os objetivos do trabalho. O exame do processo como um todo pode apontar problemas que não eram conhecidos, tais como gargalos, redundâncias e atividades desnecessárias. Os mapas gerados não são um fim em si mesmo, mas um meio para visualizar oportunidades e subsidiar melhorias graduais e contínuas em uma operação.

O mapeamento de processos inclui: (i) análise de entrada e saída, que procura entender a transformação de bens e serviços ocorrida no interior do processo; e (ii) fluxogramas, que procuram descrever o fluxo de informação e a tomada de decisão dentro da operação estudada. O fluxograma procura identificar as atividades que compõem um processo, entender seu funcionamento interno, entender as interfaces entre as atividades, identificar eventuais gargalos e descrever as relações existentes entre processos que se comuniquem. O fluxograma permite compreensão detalhada das etapas que as atividades percorrem, registrando 
estágios nas passagens de informação e de materiais, produtos ou serviços consumidos e resultados produzidos pela operação (SLACK et al., 2002).

Outra técnica que tem sido utilizada para otimização de processos empresariais é a reengenharia de processos. A reengenharia vai além da racionalização ou simplificação de atividades. Não é seu objetivo propor mudanças graduais ou contínuas em uma operação: seu objetivo é o reprojeto radical do modo como um produto ou serviço é produzido, geralmente apoiado em novos instrumentos de gestão, tais como as tecnologias integradas de informação (DAVENPORT, 1994). A reengenharia de processos é o repensar fundamental dos objetivos e dos meios para alcançá-los, implicando o redesenho radical dos processos empresariais. Seu objetivo é alcançar drásticas melhorias em indicadores críticos de desempenho, tais como custos, qualidade atendimento e velocidade (HAMMER; CHAMPY, 1994).

Slack et al. (2002) também mencionam a abordagem radical de melhoria, usando o termo reengenharia de processos de negócios (Business Process Reengineering - BRP). O BRP tem sido responsável por melhoramentos radicais no desempenho das operações, mas também tem sido criticado, principalmente pela pouca atenção dada ao problema da redução de funcionários por downsizing. Outra crítica é que sua natureza radical pode extirpar importantes experiências do corpo da operação que podem ser úteis no novo formato (KIM; JANG, 2002). O mapeamento pode ser útil como forma de entendimento e comunicação do processo atual, antes da proposição de iniciativas de reengenharia (DAVENPORT, 1994).

A reengenharia de processos pode requerer mudanças culturais na organização, exigindo mais ênfase no desempenho operacional. Também exige mais objetividade na medição de resultados, dá mais importância aos resultados finais e menos aos intermediários e gera uma nova distribuição de poder na organização. A reengenharia é mais abrangente e mais ambiciosa do que a racionalização gradual dos processos, mas exige mais mudanças e mais flexibilidade da empresa. Apesar das diferenças de enfoque, ambas podem ser combinadas. Organizações podem combinar iniciativas de melhoria incremental com reengenharia de processos, mesclando ganhos de curto prazo originados de 
pequenos esforços com ganhos de longo prazo, originados de mudanças radicais (DAVENPORT, 1994).

\section{A PESQUISA}

A pesquisa ocorreu em uma empresa prestadora de serviços de cobranças judiciais e extrajudiciais. Seus principais clientes são empresas de varejo, instituições bancárias e de financiamentos de veículos. Com mais de oitocentos colaboradores, a empresa atua na cobrança de financiados inadimplentes. Sua estrutura atual foi atingida em 2000 e hoje atua em nove estados. É objetivo da empresa que os clientes recuperem seu crédito e os inadimplentes sejam tratados com respeito. O organograma funcional da empresa é apresentado na Figura 1.

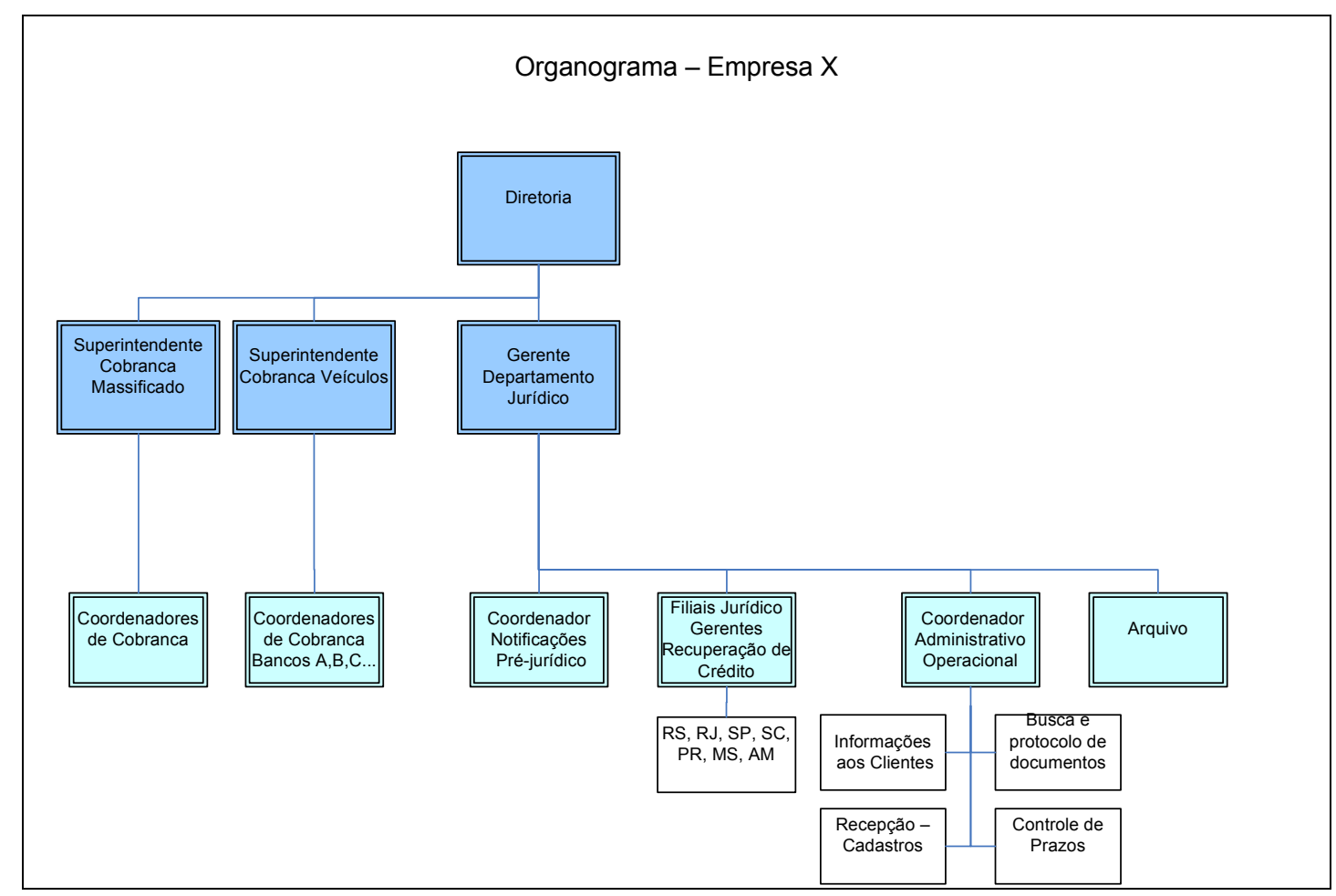

Figura 1: Organograma funcional da empresa

A estrutura de comando inclui Diretoria, Superintendência de Cobrança Massificada, Superintendência de Cobrança Veículos e Gerência Jurídica. A empresa preferiu separar as cobranças em judiciais e extrajudiciais. As cobranças 
extrajudiciais ficam sob a superintendência de cobrança, subdividida em dois grupos: cobrança massificada, oriunda de financiamentos a empresas de varejo (Casas Bahia, Lojas Colombo, Ponto Frio etc.); e financiamentos diretos de veículos (Finasa, Banco Votorantim etc). O departamento jurídico atua se não houver sucesso na cobrança extrajudicial.

\subsection{Os processos da empresa}

Para conhecer o funcionamento da empresa, mapeou-se seu processo de negócio, conforme a Figura 2. À direita tem-se o processo principal, que é a cobrança. Com base nos requisitos legais e nos requisitos de clientes, a área comercial prospecta novos clientes e trabalha para que os atuais estejam satisfeitos. $\mathrm{Na}$ área operacional, as equipes de cobrança tentam recuperar os valores devidos.

O processo pode entrar diretamente no departamento jurídico, caso a etapa de cobrança já tenha sido esgotada antes do contrato ter entrado na empresa. Devido a esta particularidade, o processo principal se divide em dois, após a área comercial cumprir sua etapa. É possível que o processo saia do operacional e vá para o jurídico e vice-versa, representado pelo caminho de mão dupla entre estes departamentos. 


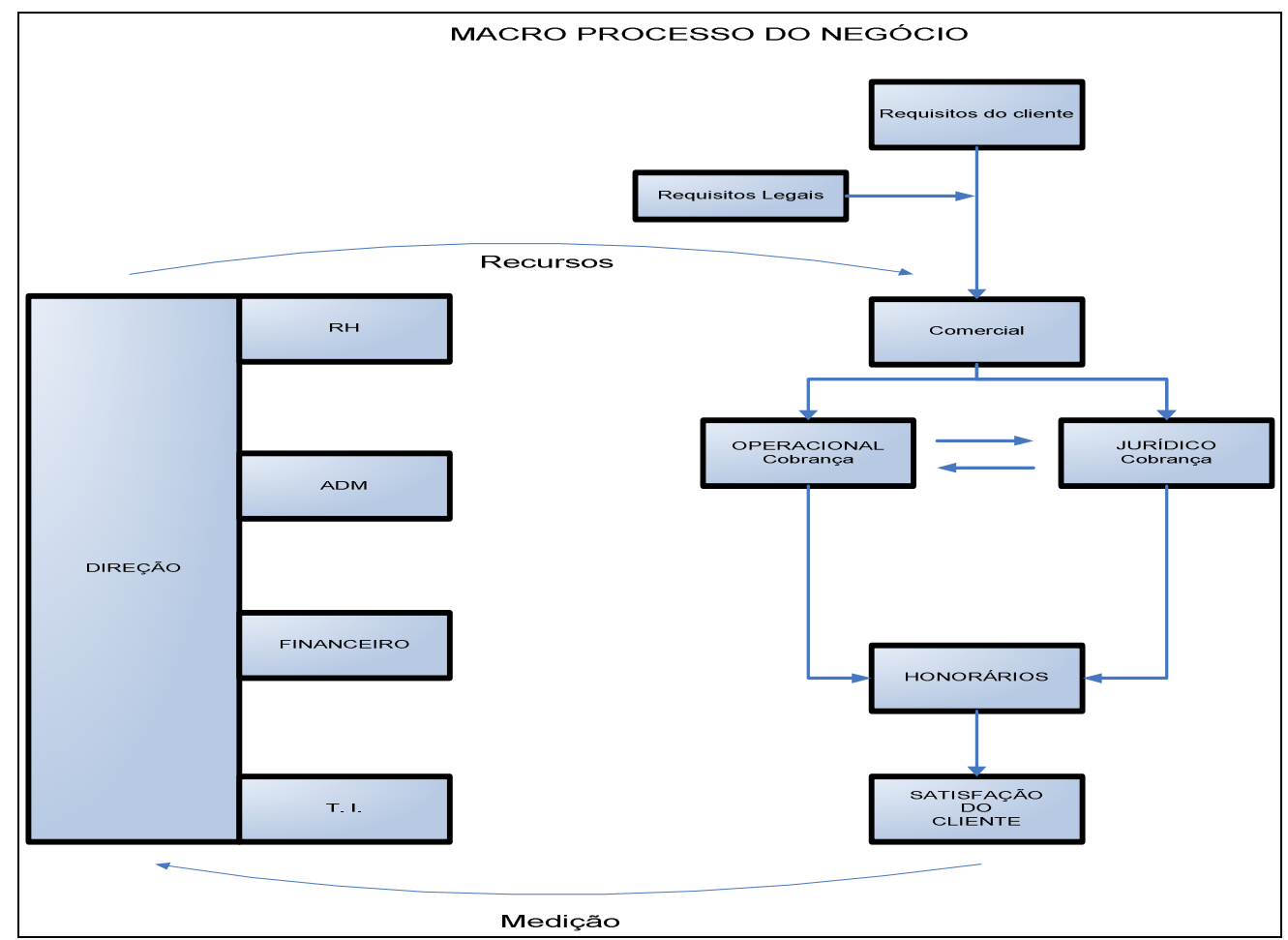

Figura 2: Processo de negócio da empresa

O processo principal é sustentado por processos de apoio: Direção, responsável pelas diretrizes, políticas da empresa, metas de desempenho e relação com os clientes; Recursos Humanos, responsável por recrutar, selecionar, treinar e avaliar os recursos humanos da organização; Administrativo, responsável pelos controles operacionais e financeiros, compras, contabilidade, gerenciamento dos resultados; Financeiro, responsável pela tesouraria, conciliações bancárias; e Tecnologia da Informação, responsável por instalar, manter e atualizar os recursos tecnológicos de hardware e software e prover a direção de relatórios.

\subsection{A proposta}

A maior dificuldade da empresa é atender aos prazos exigidos pelos clientes, desde a entrada do contrato na função cobrança até o ajuizamento da causa. Entre o processo de cobrança e o processo jurídico há uma relação de fornecedor-cliente interno. O objetivo de pesquisa se limitou a mapear o processo jurídico. A Figura 3 mostra a trajetória dos contratos de cobrança passando através da estrutura funcional da empresa. 


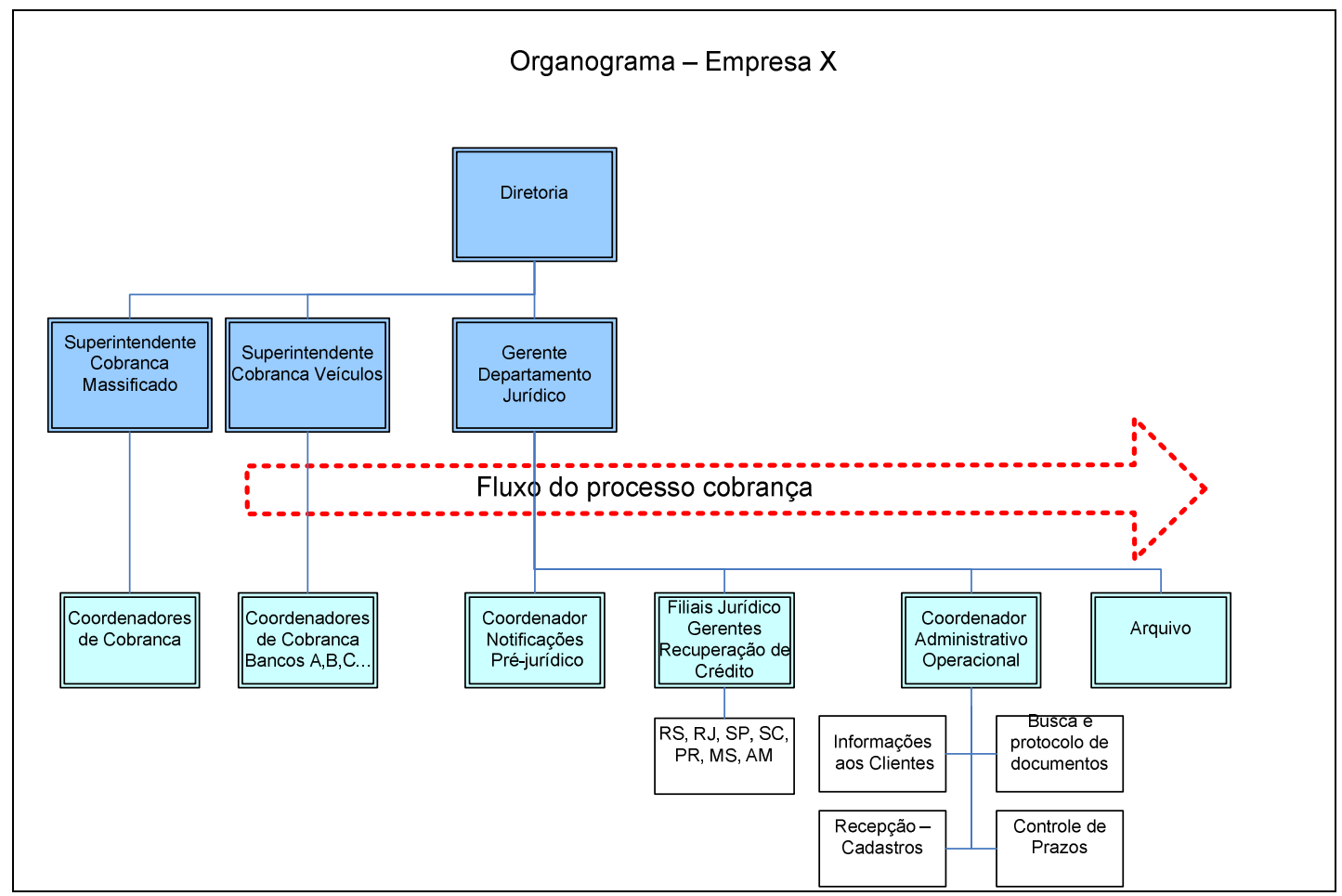

Figura 3: Fluxo do processo de cobrança através dos departamentos da empresa.

O tempo de atraso para considerar inadimplente um contrato é fixado por cada cliente. O mais usual é trinta dias. Os contratos de cobrança entram na empresa pelo setor de Cobrança Veículos, onde ficam por quinze dias. Neste período, a equipe de cobradores liga para os financiados tentando o pagamento do débito. Obtendo sucesso, o contrato é devolvido ao banco, que paga os honorários do serviço prestado. Do contrário, o contrato é encaminhado ao Setor de Notificações, também chamado de Pré-jurídico.

Os clientes avaliam a performance da empresa com base em uma régua de ajuizamento de ações. Esta régua é o prazo que a empresa possui para distribuir a ação judicial de cobrança, na comarca, partindo da data de recebimento do contrato.

Aqui reside uma dificuldade. Geralmente, os clientes têm exigido ajuizamento em até noventa dias. Como os contratos chegam após trinta dias de atraso da parcela e permanecem por quinze dias em cobrança extrajudicial, restam no máximo quarenta e cinco dias para os departamentos pré-jurídico e jurídico cumprirem suas etapas. 
A Figura 4 sintetiza como os clientes medem o desempenho da empresa. A Figura 5 apresenta o fluxograma do processo jurídico.

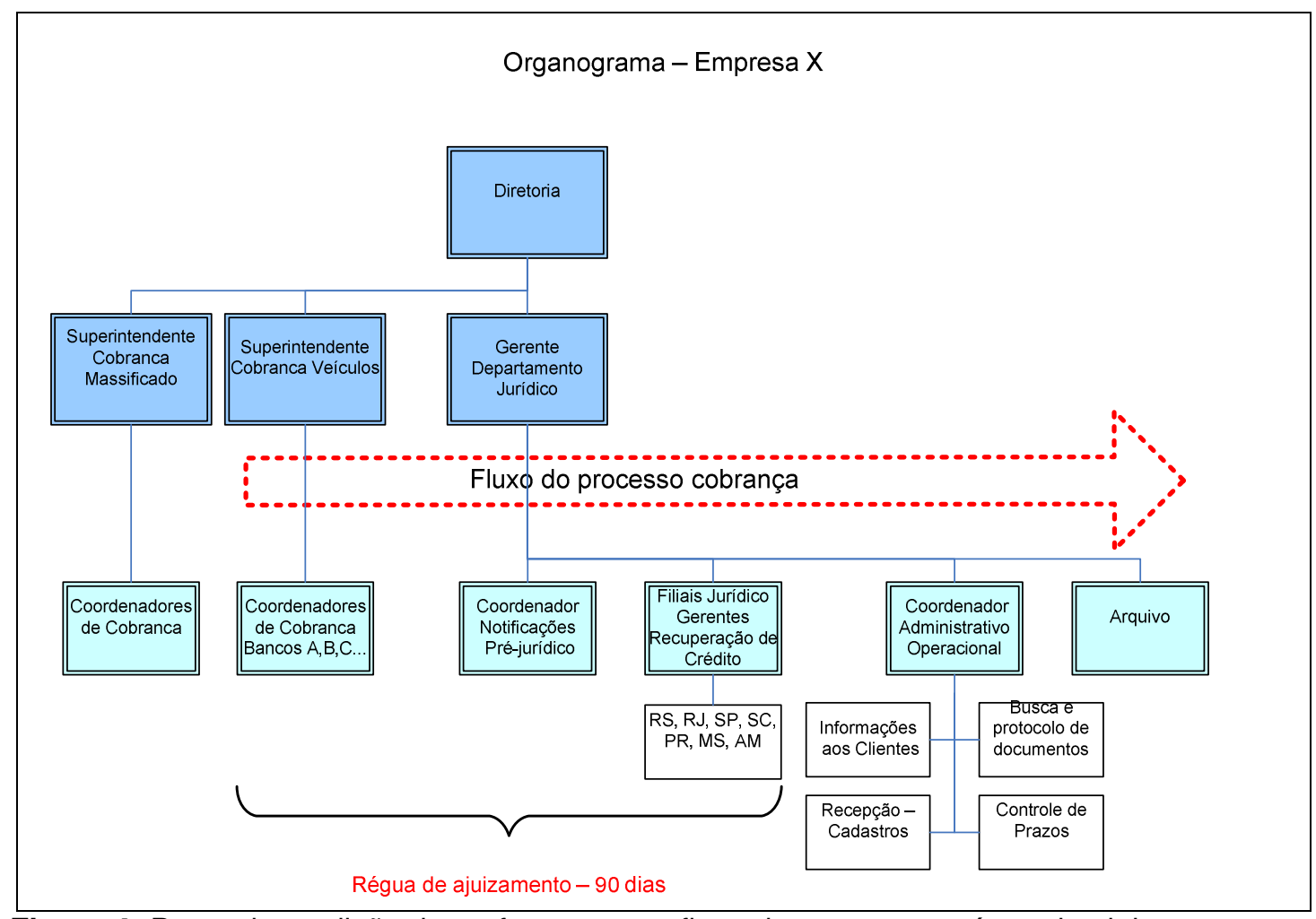

Figura 4: Ponto de medição de performance no fluxo do processo - régua de ajuizamento 


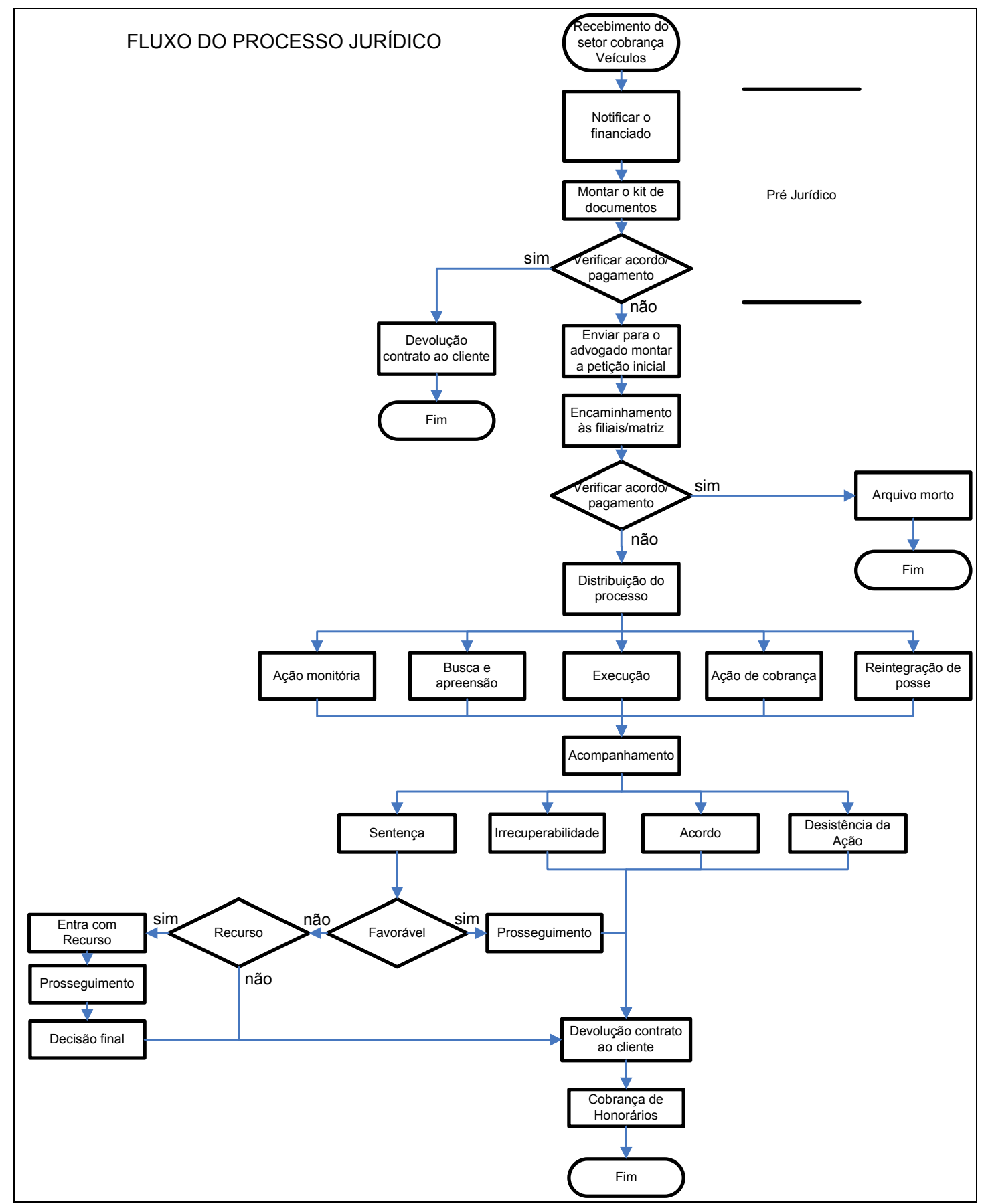

Figura 5: Fluxograma do processo do departamento jurídico.

Com base apenas na visão geral do processo, não foi possível detectar onde e quando se apresentam as maiores dificuldades para cumprir o prazo exigido de quarenta e cinco dias. Foi necessário desdobrar as atividades de cada fase do processo. Iniciou-se pelo fluxo detalhado das atividades do processo jurídico, ou seja, o fluxo da entrada, processamento e saída do setor de Notificações. Após o 
mapeamento do processo, utilizando-se entrevistas com colaboradores do setor, desenhou-se o fluxograma da situação atual, apresentado na Figura 6.

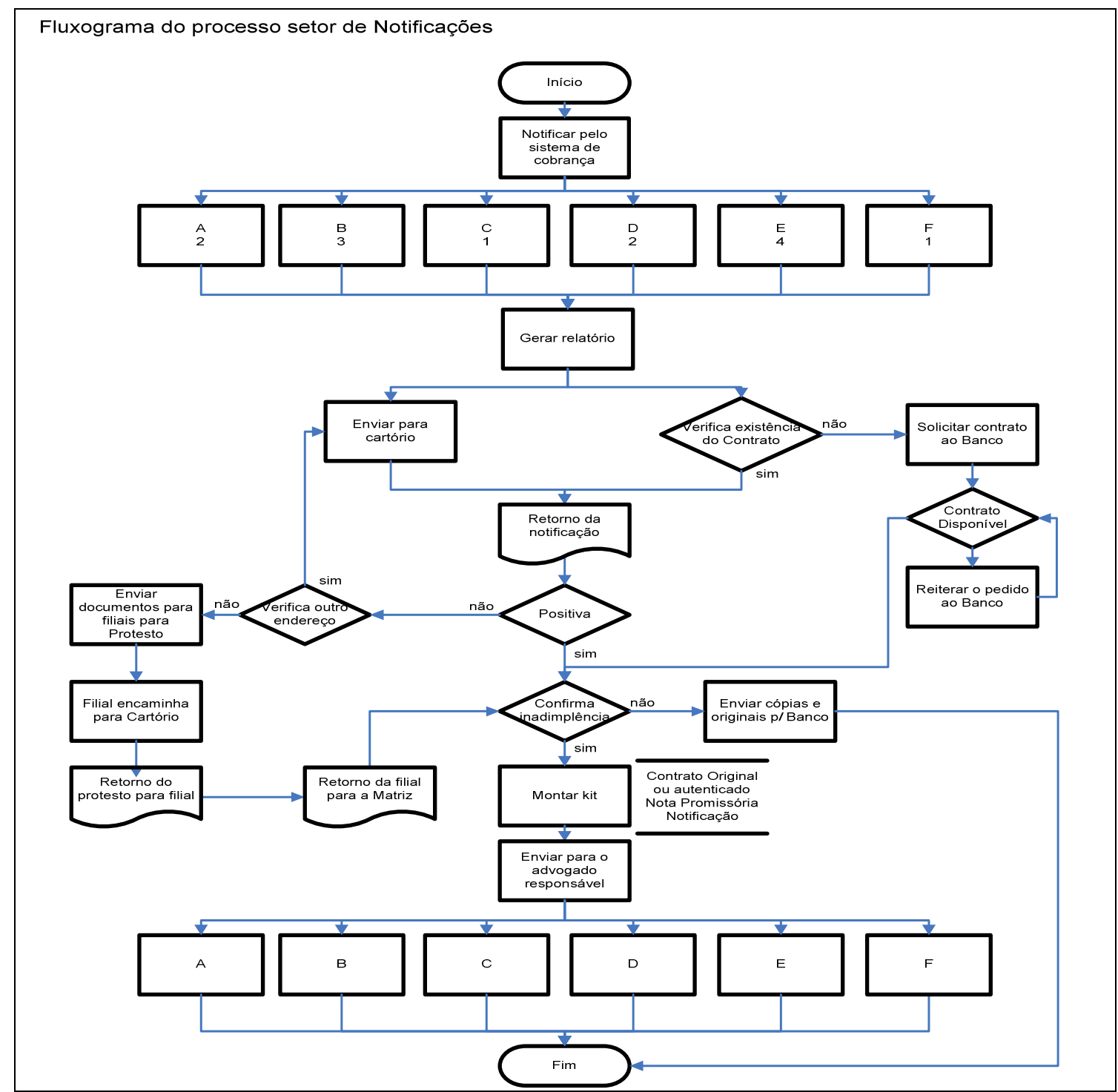

Figura 6: Fluxograma do Setor de Notificações

O setor de Notificações é responsável por constituir o cliente em mora, ou seja, documentar por notificação judicial que o financiado possui uma dívida junto à instituição financeira. Isso implica gerar o relatório no sistema informatizado de cobrança, expedir correspondência para o cartório da comarca do financiado com os dados necessários para que o cartório efetue a notificação, aguardar o retorno deste documento, solicitar a documentação necessária aos bancos, juntar toda a documentação, verificar se a inadimplência persiste, pois o cliente pode ter pago 
durante o período, montar o chamado kit de processo e enviar ao advogado responsável por montar a peça judicial. Montada a peça, o advogado pode finalmente ajuizar a ação.

Pelo mapeamento, detectou-se porque que os prazos que o cliente exige dificilmente são cumpridos. O tempo que os contratos permanecem no setor de Notificações muitas vezes supera os quarenta e cinco dias. Também se identificou que, para cada cliente, existe uma equipe de trabalho que realiza todas as etapas do processo: contratos oriundos do banco ou loja A são conduzidos pela equipe $A$ em todas as etapas do processo de Notificação. Isso implica que se a empresa captar mais um cliente terá que formar mais uma equipe. Optou-se em apresentar este processo em apenas um fluxograma individualizando entradas e saídas por cliente, pois nas demais etapas do processo as atividades são idênticas. Na entrada do processo, informa-se no bloco de cada banco o número de colaboradores que executam as tarefas do processo de Notificação, totalizando treze colaboradores para seis clientes mais um supervisor. Atualmente, o setor opera com quatorze pessoas.

Um problema menor foi detectado no departamento jurídico: os kits com as documentações necessárias para o ajuizamento dos processos eram recebidos pelo advogado e, muitas vezes, ficavam até duas semanas a espera que este providenciasse um ou mais documentos faltante para elaborar a petição inicial. Às vezes, a falta era tão simples quanto o pagamento da guia de encaminhamento do processo ao cartório. Tal procedimento toma tempo de profissional qualificado e oneroso, com tarefas que poderiam ser feitas por profissionais de menor qualificação.

Um problema maior foi detectado no setor de Notificações.

Um gargalo pode surgir quando entram ao mesmo tempo muitos contratos do mesmo cliente. Resultam filas de contratos aguardando os documentos necessários em uma equipe, enquanto outras estão com carga normal de trabalho e até mesmo com ociosidade. Para exemplificar, a equipe A está dimensionada para notificar cinqüenta contratos por dia e durante a pesquisa, em um mesmo dia, entraram cem contratos. Surgiu uma fila de espera e uma pressão por resultados nesta equipe, enquanto outras tinham membros ociosos. 
Com tal fluxo, descontínuo e desequilibrado, surgia um problema no departamento jurídico, pois este depende de pré-requisitos gerados no setor de Notificações para iniciar o seu trabalho. Havia períodos em que o excesso de carga recebida inviabilizava o cumprimento de prazos, enquanto em outros períodos a falta de processos causava ociosidade.

Tais evidências foram consideradas suficientes para justificar as atividades de modificações e melhorias adotadas no processo de Notificações.

\subsection{0 novo processo}

Com base nos conceitos de processos, gargalos e reengenharia de processos, formulou-se uma nova proposta de estrutura e processos no departamento jurídico. Propôs-se um novo organograma, conforme a Figura 7.

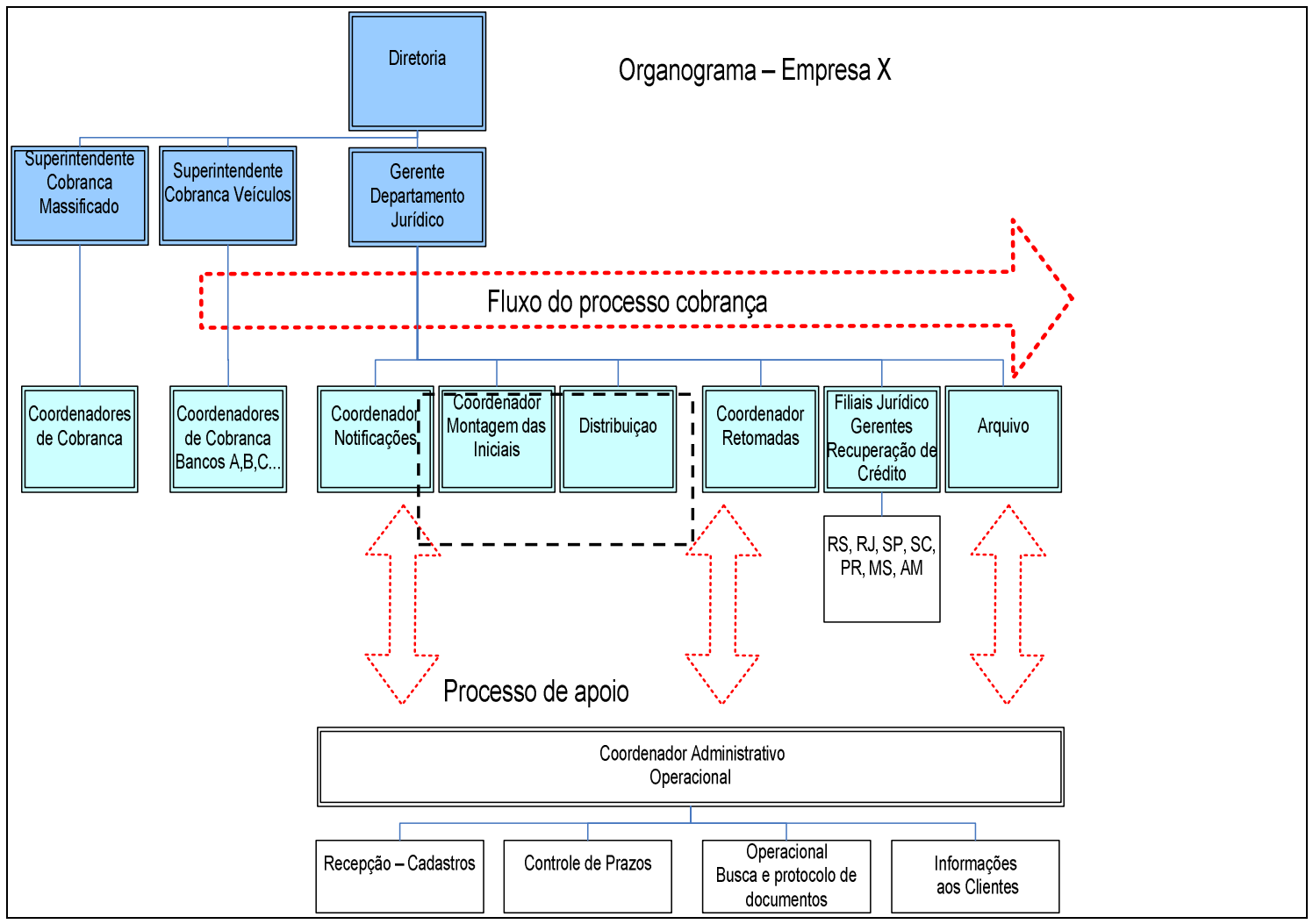

Figura 7: Proposta de novo organograma da empresa 
Na nova estrutura, em comparação com a da Figura 3, surgiram mais dois processos, assinalados com o traçado pontilhado preto na Figura 7. Criou-se o setor de Montagem das Iniciais (INI), uma linha de montagem de petições iniciais, e um setor de Distribuição (DIS), responsável por pagamento de guias processuais e protocolos nas comarcas. Desta forma, reduziram-se atividades de menor valor agregado no departamento jurídico, passando-as ao departamento pré-jurídico, onde agora passaram a ser realizadas por pessoal administrativo, que percebe remuneração menor do que os advogados. Otimizaram-se as funções dos advogados do departamento jurídico, focando-os nas atividades em que agregam mais valor ao processo. Separaram-se as atividades do pré-jurídico das atividades eminentemente técnicas, nas quais é necessário conhecimento profissional em direito.

Também foi proposta uma reformulação interna no setor de Notificações. A Figura 8 apresenta o novo fluxograma do setor, passando pelos três setores de atividades pré-jurídicas. A saída do processo do departamento pré-jurídico para o departamento jurídico ocorre no momento da inserção da informação no sistema jurídico, ou seja, efetuado o protocolo. Tal atividade também é chamada de distribuição. Ao registrar o protocolo no sistema jurídico, o advogado responsável recebe a informação de que o processo passa a ser judicial e que ele é o responsável por sua condução junto à justiça.

Especificamente para o setor de Notificações, propôs-se o formato de trabalho da Figura 9. Este formato acaba com a verticalização das atividades até então adotada, na qual havia uma equipe específica para cada cliente. No novo desenho, dividiu-se o setor em três funções específicas em seqüência lógica, segundo o fluxo das atividades. A equipe foi treinada para atendimento ao processo geral de Notificação e não às rotinas de notificação de cada banco. 


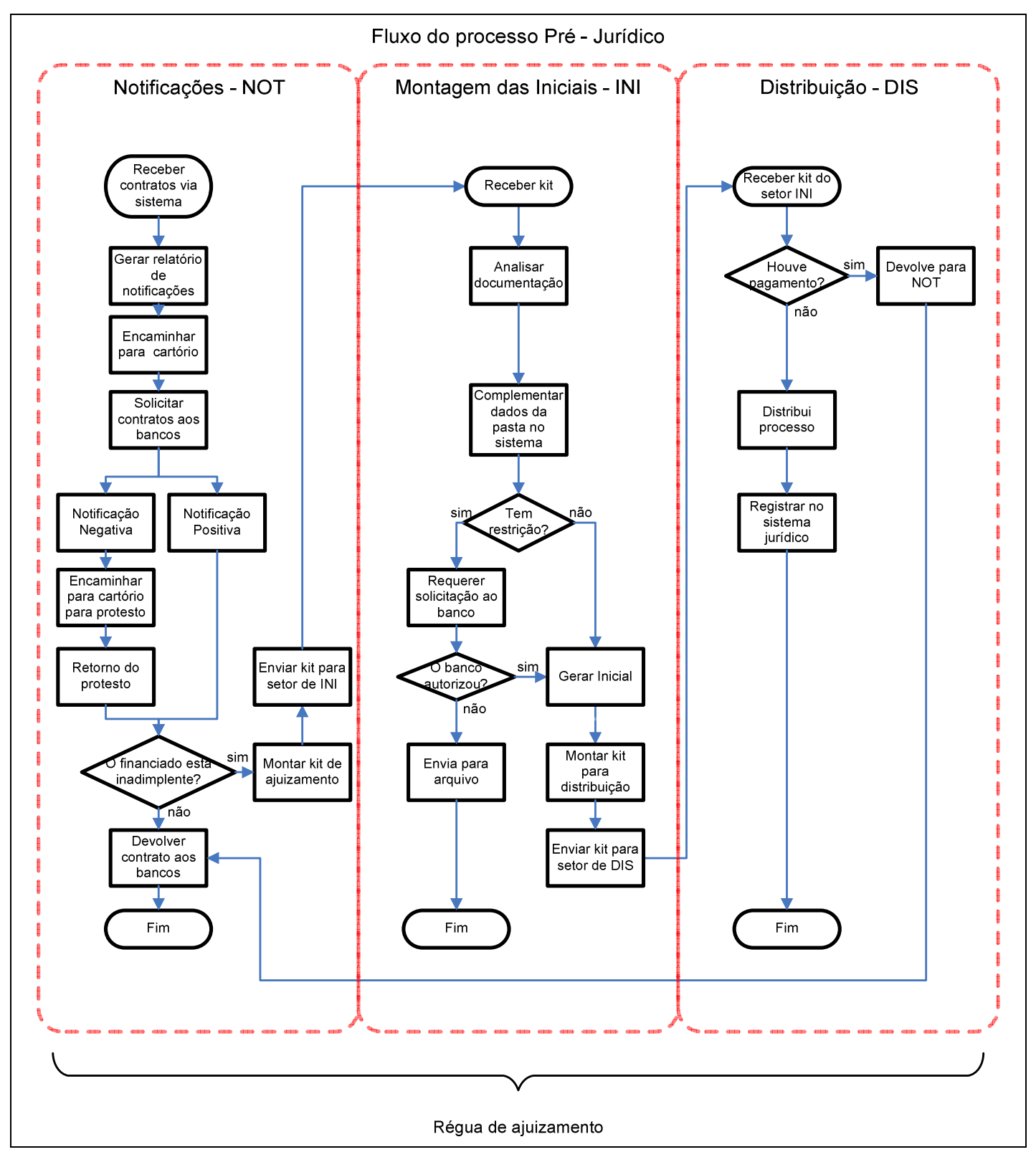

Figura 8: Fluxograma das interligações dos processos pré-jurídicos.

Revista Produção Online, v.10, n.3, p. 524-550, set., 2010 


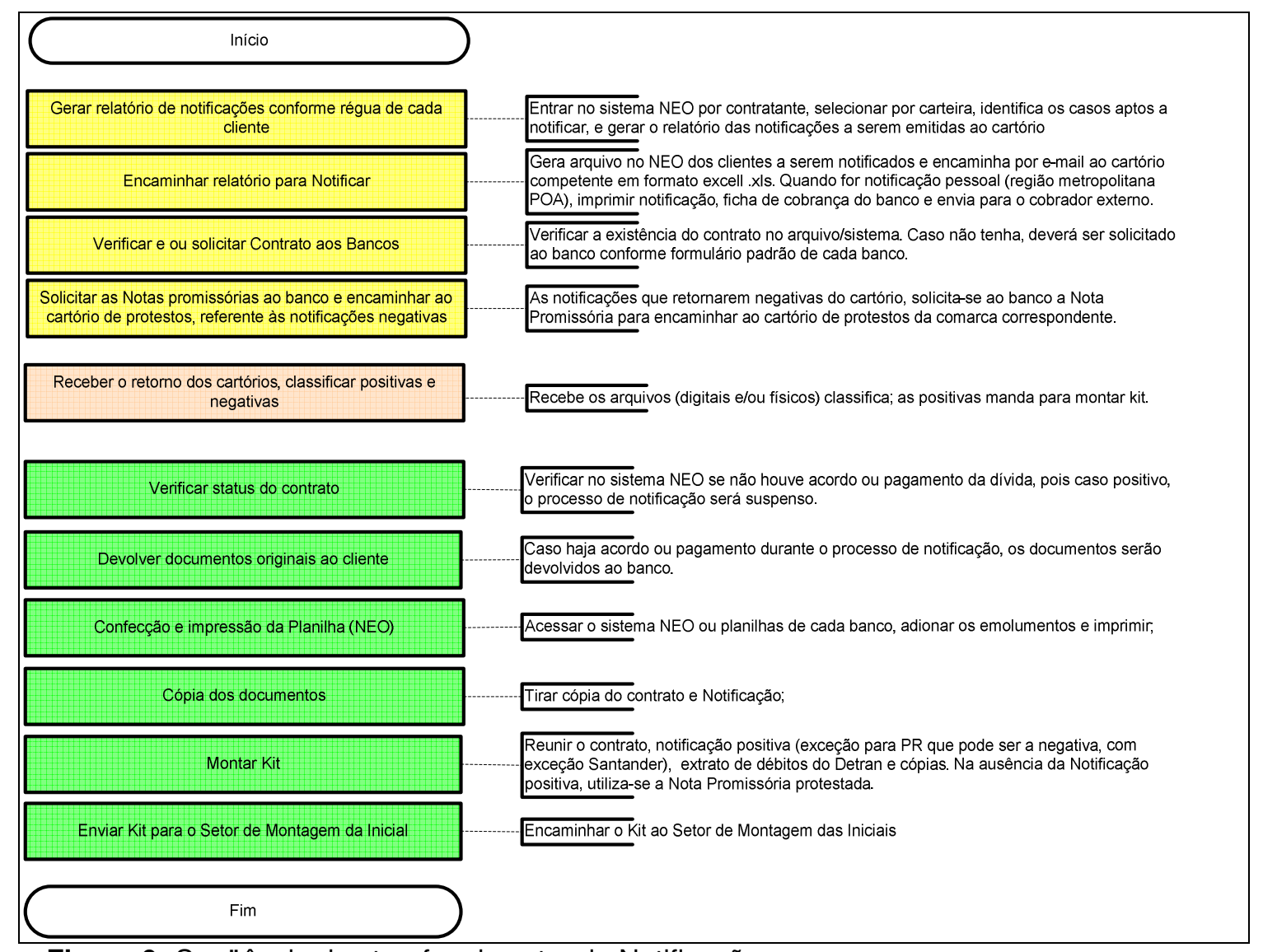

Figura 9: Seqüência das tarefas do setor de Notificações.

A primeira equipe cumpre as quatro primeiras atividades do desenho. É formada por três pessoas, tem a função de gerar relatórios de financiados a notificar, encaminhar o relatório ao cartório responsável, notificar, verificar a existência do contrato e demais documentações necessárias para montagem do kit, solicitar aos bancos os documentos que faltam e solicitar as notas promissórias caso a notificação expedida retorne negativa.

A segunda equipe é formada por uma pessoa e é responsável pela tarefa de receber as notificações que voltam de cartórios, classificá-las e dar andamento nas positivas. Houve remoção de um foco de ineficiência. Agora só seguem adiante para a montagem dos kits o que realmente é passível de virar peça judicial. As demais notificações retornam para a primeira equipe efetuar o protesto, que é uma operação semelhante à de notificação. Isso elimina trabalho desnecessário da equipe posterior e dos advogados. Esta equipe também é responsável por receber e organizar os 
documentos oriundos dos bancos. Da mesma forma, caso esteja faltando algum documento, o processo não segue, evitando trabalhos inúteis.

A terceira equipe cumpre as seis atividades restantes. É composta por três colaboradores responsáveis pela montagem física do kit de ajuizamento. Antes de iniciar o kit, a equipe faz buscas no sistema para certificar-se de que o financiado permanece inadimplente. Isso agiliza o processo, pois antes, muitas vezes, o kit era montado, mas o financiado pagara as parcelas em atraso, ou ao menos uma parte delas. Houve a remoção de mais uma ineficiência, pois agora só vão para os advogados os kits ainda inadimplentes, ou com valor correto da dívida. Caso nesta fase seja feito o pagamento ou surja outro motivo para a desmontagem do kit, a documentação é devolvida aos clientes. Cumpridas estas etapas, a equipe reúne a documentação, monta o kit e envia para o setor de Montagem das Iniciais - Ml.

As modificações apontadas podem equilibrar mais as atividades, pois agora existe uma equipe para cada etapa do processo, ao invés de uma equipe para cada cliente. Com equipes distribuídas por processos, eventuais sobrecargas e ociosidades geradas por clientes são compensadas, obtendo-se um fluxo mais equilibrado e contínuo ao longo do processo. Todos os contratos de todos os clientes entram no fluxo de atividades da primeira equipe e seguem o fluxo lógico das tarefas. Ou seja, mesmo que exista a possibilidade de um cliente demandar cinqüenta contratos em um dia, cem no outro e dez no terceiro, a soma dos seis clientes compensa tais variações, pois é quase impossível todos demandarem quantidades muito acima ou muito abaixo das usuais no mesmo dia. Isso possibilita um melhor equilíbrio das atividades de toda a equipe. Neste novo formato, a proposta é que se trabalhe com oito pessoas sendo sete na operação e uma na supervisão. Isso significa uma redução de custos na ordem de $40 \%$ em gastos com pessoal.

O fluxograma das atividades do setor de Notificações passou a ser único para todos os clientes, facilitando o entendimento e a comunicação, inclusive com os colaboradores. O novo desenho é apresentado na Figura 10. 


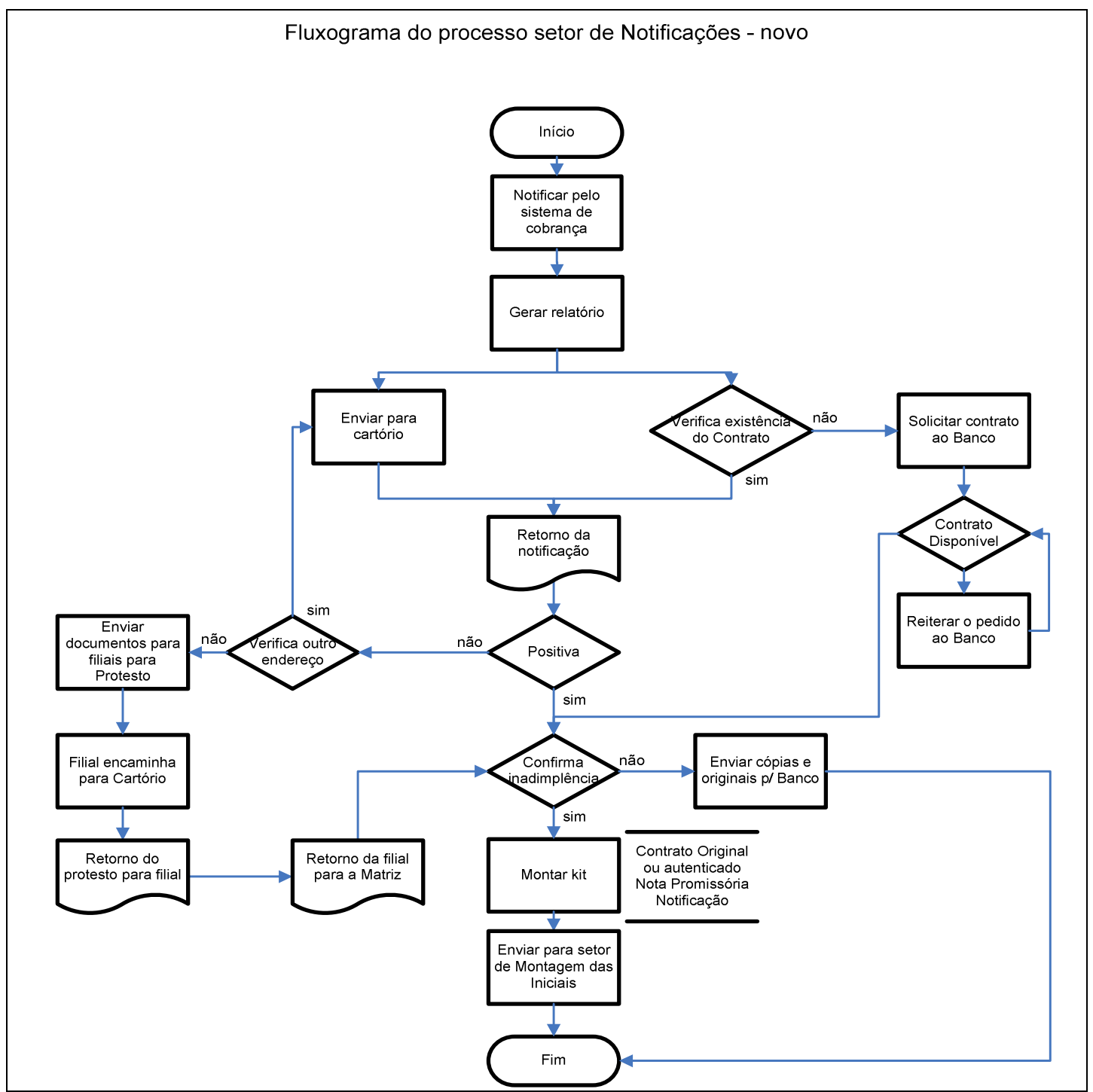

Figura 10: Novo fluxograma do processo de notificações

\subsection{Discussão}

Dois aspectos podem ser discutidos, os impactos da mudança junto aos colaboradores e os resultados numéricos da intervenção, pela medição do novo prazo de entrega. Tais resultados foram observados apenas uma vez, seis meses após a intervenção, já então consolidada. A redução de funcionários e por conseqüência de custos, apesar de útil, não era objetivo inicial de pesquisa e foi considerada pela empresa como ganho colateral. Mesmo aumentando a margem de lucro da empresa, esta redução de custo pouco contribuiu para a competitividade no 
setor, pois esta é, segundo os gestores, determinada mais pela velocidade de entrega do que pelo preço do serviço.

Quanto ao primeiro aspecto, durante a intervenção, por entrevistas com colaboradores dos setores estudados, foram observadas algumas resistências à nova forma de enxergar a empresa como um conjunto de processos e não como um conjunto de funções. Alguns colaboradores preferem considerar-se como profissional cumpridor de tarefas, não como agente de resultados. Por exemplo, um colaborador experiente declarou que se considera arquivista e que aceita vários tipos de manejo de arquivos, segundo várias tecnologias, mas não se considera um agente pré-jurídico, como proposto na mudança. Este colaborador não aceita, por exemplo, ir pagar taxas em banco, mesmo que esta tarefa esteja trancando um lote de processos e que não haja arquivamentos a serem feitos no momento. Antes da mudança, muitas vezes, tal atividade era feita por advogados, com qualificação e remuneração muito superiores à do entrevistado.

De modo geral, vale destacar três aspectos que foram observados nas entrevistas: (i) houve insegurança perante a possibilidade de demissão, o que fez com que alguns colaboradores escondessem informações sobre as tarefas, para que a empresa ficasse refém de suas competências e conhecimentos; (ii) a falta de visão sistêmica da organização como um grande conjunto de processos fez com que alguns colaboradores simplesmente não se interessassem em saber o que ocorre antes ou depois de sua atividade; e (iii) houve dificuldade de colaboradores em se adaptar a controles dos resultados operacionais da empresa, medidos segundo critérios e por meio de indicadores objetivos de mensuração de resultados de cada etapa de seus principais processos.

Tais aspectos haviam sido identificados na literatura sobre reengenharia, Como transcendem ao objetivo de pesquisa, são remetidos à continuidade.

Quanto aos resultados numéricos, definiu-se como indicador de desempenho da intervenção o prazo de atendimento de contratos. O prazo inicia quando o cliente remete o contrato e encerra quando este é registrado no sistema jurídico. Cobranças extrajudiciais bem-sucedidas não entram no indicador, pois sempre se encerram em até quinze dias. 
Usualmente, a empresa não mede este indicador e nem tem procedimento automático em seu sistema de informação para tanto. Foram necessárias medições puntuais, feitas segundo procedimentos manuais de cálculo, uma antes e uma depois da intervenção. Em média, a empresa recebe duzentos processos por dia e sua tabulação manual é onerosa, por isto as medições foram exclusivas, não sistematizadas. Se a empresa decidir automatizar o cálculo, este indicador poderá ser acompanhado permanentemente.

A primeira medição incluiu os dois meses anteriores à mudança. A segunda medição incluiu um único mês, seis meses após a mudança. Esperou-se que os processos se estabilizassem após os efeitos da mudança. O resultado é apresentado na Tabela 1. Observa-se que o prazo médio de atendimento caiu de 61 para 40 dias e que o percentual de atendimentos dentro do prazo de quarenta e cinco dias subiu de 12 para $81 \%$. Tal resultado apóia a hipótese de que a intervenção foi bem sucedida, ressalvando-se que, para uma definição sobre o sucesso, é necessário que a empresa meça sistematicamente este indicador.

\begin{tabular}{ccc} 
Tabela 1: Resultados numéricos comparados \\
\hline medição & $\begin{array}{c}\text { média para o prazo } \\
\text { de entrega }\end{array}$ & $\begin{array}{c}\text { percentual de } \\
\text { atendimentos no } \\
\text { prazo }\end{array}$ \\
\hline antes & 61 dias & $12 \%$ \\
depois & 40 dias & $81 \%$ \\
\hline
\end{tabular}

\section{CONSIDERAÇÕES FINAIS}

O objetivo deste artigo foi sugerir melhorias que pudessem reduzir os prazos de atendimento de uma empresa de cobrança. Os objetivos específicos foram: (i) mapear os atuais processos; (ii) identificar ineficiências que atrasam o processo; (iii) propor melhorias; e (iv) monitorar os primeiros resultados. O método de pesquisa foi o estudo de caso. Durante a pesquisa e análise do tema, ficou claro que os objetivos de pesquisa poderiam se valer de conhecimentos ligados à análise e melhoria de 
processos de negócio. Diante das informações coletadas na pesquisa, ficou evidente a existência de falhas nas transições entre departamentos, o que gerava atrasos nos prazos da prestação dos serviços.

O mapeamento dos processos identificou importantes gargalos, além de má organização funcional do setor pré-jurídico. As proposições resultantes possibilitaram ganhos imediatos, tais como: (i) otimização dos recursos humanos no setor de notificações, com redução em torno de $40 \%$ dos custos com mão-de-obra no setor; (ii) organização e equilíbrio no fluxo de trabalho entre os colaboradores do setor; (iii) mais agilidade na execução dos trabalhos, acabando com as filas de contratos e com as ociosidades temporárias; (iv) transferência para a empresa do conhecimento centralizado nos colaboradores, pelo fato de somente uma equipe conhecer o fluxo do processo de determinado cliente; e (v) criação de setores dentro do pré-jurídico que possam fazer os preparos administrativos e otimizar o uso dos advogados.

Apesar da falta de parâmetros intermediários de medição, percebeu-se que as filas de trabalho saíram do setor de notificação. Ou seja, com a melhoria do fluxo, gargalos migraram para os setores posteriores, o que confirma que o processo alterado foi melhorado. A redução na média do prazo final de atendimento reforçou esta conclusão.

O mapeamento dos processos abriu possibilidades de novas pesquisas. Uma delas é o aprofundamento dos estudos de desenvolvimento de fornecedores, tais como os cartórios, fornecedores de serviço de notificação judicial na comarca do financiado. Este fornecedor representa parte importante na fase pré-jurídica do processo. Outra alternativa de pesquisa é a especificação de um sistema de indicadores de desempenho para o monitoramento e controle permanente do prazo de atendimento. Por fim, sugere-se também mais pesquisa acerca do efeito de tais mudanças em colaboradores e que se criem métodos que facilitem a adesão dos mesmos a mudanças organizacionais. 


\section{REFERÊNCIAS}

ADESOLA, S.; BAINES, T. Developing and evaluating a methodology for business process improvement. Business Process Management Journal, v.11, n.1, p. 3746, 2005.

CRUZ, T. Sistemas métodos e processos: administrando organizações por meio de processos de negócios. São Paulo: Atlas, 2003.

CRUZ, T. Workflow II: a tecnologia que revolucionou processos. Rio de Janeiro: Epapers Serviços Editoriais Ltda., 2004.

DAVENPORT, T. Reengenharia de processos: como inovar na empresa através da tecnologia da informação. Rio de Janeiro: Campus, 1994.

DAVENPORT, T. Missão crítica: obtendo vantagem competitiva com os sistemas de gestão empresarial. Porto Alegre: Bookman, 2002.

GALLINA, D.; BRODBECK, A.; MAÇADA, A.; HOPPE, N. Gerenciamento de processos e integração de aplicações na logística. In: CATI - CONGRESSO ANUAL DE TECNOLOGIA DA INFORMAÇÃO, 2006, São Paulo. Anais... São Paulo: FGV/EAESP, 2006.

GOLDRATT, E.; COX, J. Manual da teoria das restrições. Porto Alegre: Bookman, 2002.

GONÇALVES, J. As empresas são grandes coleções de processos. Revista de Administração de Empresas - RAE, v. 40, n.1, p. 6-19, jan./mar., 2000.

HAMMER, M.; CHAMPY, J. Reengenharia: revolucionando a empresa em função dos clientes, da concorrência e das grandes mudanças da gerência. Rio de Janeiro: Campus, 1994.

JOHANSSON, H. Processos de negócios. São Paulo: Pioneira, 1995.

KIM, S.; JANG, K.: Designing performance analysis and IDEF0 for enterprise modelling in BPR. International Journal of Production Economics, v. 76, n.1, p.121-133, 2002.

PAIVA, E.; CARVALHO, L; FENSTERSEIFER, J. Estratégia de produção e de operações. Porto Alegre: Bookman, 2004. 
PINHO, A.; LEAL, F.; ALMEIDA, D. A Integração entre o Mapeamento de processo e o mapeamento de falhas: dois casos de aplicação no setor elétrico. ENEGEP ENCONTRO NACIONAL DE ENGENHARIA DE PRODUÇÃO, 26., 2006. Anais... Fortaleza: ABEPRO, 2006.

RINALDI JR., R. Projeto ou processo: questão de escolha. HSM Management. fev. 2006. Disponível em: <http://www.hsm.com.br/editorias/processos/projeto ou_proc.php>. Acesso em: 04 fev. 2009.

ROESCH, S. Projetos de estágio e de pesquisa em administração: guia para estágios, trabalhos de conclusão, dissertações e estudos de caso. São Paulo: Atlas, 1999.

SLACK, N.; CHAMBERS, S.; JOHNSTON, R. Administração da Produção. São Paulo: Atlas, 2002.

TRIVIÑOS, A. Bases teórico-metodológicas preliminares da pesquisa qualitativa em ciências sociais. Porto Alegre: Faculdades Ritter dos Reis, 2001.

WERKEMA, M. Ferramentas estatísticas básicas para o gerenciamento de processos. Belo Horizonte: Fundação Christiano Ottoni, 1995.

YIN, R. Estudo de caso: planejamento e métodos. Porto Alegre: Bookman, 2001.

ZERBINI, R. Avaliação de desempenho de fornecedores: um estudo de caso em uma grande instituição financeira brasileira. Dissertação (Mestrado)- Programa de Pós-graduação em Administração. São Paulo: FGV/EAESP, 2006.

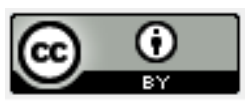

Artigo recebido em 15/04/2009 e aceito para publicação em 24/08/2010. 